\title{
Antigenic validation of recombinant hemagglutinin-neuraminidase protein of Newcastle disease virus expressed in Saccharomyces cerevisiae
}

\author{
S. A. KHULAPE, H. K. MAITY, D. C. PATHAK, C. MADHAN MOHAN, S. DEY*
}

Recombinant DNA Laboratory, Indian Veterinary Research Institute, Izatnagar, Bareilly-243122, India

Received September 25, 2014; revised March 2015; accepted July 30, 2015

\begin{abstract}
Summary. - The outer membrane glycoprotein, hemagglutinin-neuraminidase (HN) of Newcastle disease virus (NDV) is important for virus infection and subsequent immune response by host, and offers target for development of recombinant antigen-based immunoassays and subunit vaccines. In this study, the expression of HN protein of NDV is attempted in yeast expression system. Yeast offers eukaryotic environment for protein processing and posttranslational modifications like glycosylation, in addition to higher growth rate and easy genetic manipulation. Saccharomyces cerevisiae was found to be better expression system for HN protein than Pichia pastoris as determined by codon usage analysis. The complete coding sequence of $\mathrm{HN}$ gene was amplified with the histidine tag, cloned in pESC-URA under GAL10 promotor and transformed in Saccharomyces cerevisiae. The recombinant $\mathrm{HN}(\mathrm{rHN})$ protein was characterized by western blot, showing glycosylation heterogeneity as observed with other eukaryotic expression systems. The recombinant protein was purified by affinity column purification. The protein could be further used as subunit vaccine.
\end{abstract}

Keywords: Newcastle disease virus; glycoprotein; codon usage; yeast expression

\section{Introduction}

Newcastle disease (ND) is a severe respiratory disease affecting the farmed poultry and free-living birds and is a constant threat to the commercial chicken industry around the world. Special emphasis is being put forth to prevent the spread of ND by efficient biosecurity and flock management practices, development of rapid diagnostics, novel antiviral therapy and vaccination strategies (Alexander, 2008). Traditionally, antigens associated with pathogenic organisms like ND virus (NDV), are produced for the development of immunoassays and vaccines by inoculation of embryonated chicken eggs or infecting susceptible cultured cells with the

*Corresponding author. E-mail: sohinimadhan@gmail.com; phone: +91-9897749358.

Abbreviations: CUSP = create codon usage table program; Emboss = European Molecular Biology Open Software Suit; $\mathrm{HN}$ = hemagglutinin-neuraminidase; $\mathrm{ND}=$ Newcastle disease; $\mathrm{NDV}=\mathrm{ND}$ virus; $\mathrm{rHN}=$ recombinant $\mathrm{HN}$; RSCU = relative synonymous codon usage value virus followed by purification and inactivation of the virus or extraction of viral antigens. Due to potential biosecurity hazards and handling of potential pathogens, recombinant proteins have become popular as antigens to replace the traditionally inactivated viruses (Wang et al., 2006). With the development of recombinant DNA technologies, various expression systems such as bacterial, yeast, insect and mammalian hosts are available for this purpose.

The hemagglutinin-neuraminidase (HN) protein of NDV is present as outer membrane spikes and is responsible for virus attachment and host immune response. Hence, the HN protein has been explored for the development of rapid antigen detection kit and subunit vaccines. Mohan et al. (2006) expressed the HN protein of NDV in Escherichia coli, a typical prokaryotic expression system. The prokaryotic host does not offer any posttranslational glycosylation of proteins. However, the recombinant $\mathrm{HN}$ ( $\mathrm{rHN}$ ) protein expressed in E. coli was antigenically functional in an ELISA format. The $\mathrm{HN}$ protein of NDV is immunologically important as it also induces specific neutralizing antibody response (Schaper et al., 1988) and thus has a vaccination potential (Long et al., 
1986). Since, HN is present naturally in glycosylated form, and $E$. coli has no glycosylation pathway for processing nascent polypeptides, the recombinant protein often fails to fold properly, hampering the activity and yield, an important determinant towards development of a subunit vaccine.

The eukaryotic expression of $\mathrm{HN}$ protein mediated through baculovirus has been widely used, as insect cells have the ability for protein folding and post-translational modifications (Nagy et al., 1991; Niikura et al., 1991; Ong et al., 1999; Lee et al., 2008). But the failure to achieve high cell densities limited the full exploitation of the potential productive capacity of the baculovirus expression system (Radford et al., 1997). The heterologous expression of protein in mammalian system produces recombinant protein in native conformation but is expensive and has lower production level. Use of avian cells for the expression of NDV HN glycoprotein for immunization has been reported earlier (Cosset et al., 1991). Further, the full length HN gene has also been cloned into a mammalian expression vector and characterized for transient expression of protein in cell culture system by Sawant et al. (2011). In contrast, the yeast cells being single celled, has the ability for fast growth, amenable to genetic manipulation and possesses eukaryotic features including a secretory pathway leading to correct protein processing and posttranslational modifications (Mattanovich et al., 2012).

Expression of the complete coding sequence of $\mathrm{HN}$ gene of NDV has not been reported in yeast. King (2004) described the absence of HN protein expression in Pichia pastoris and S. cerevisiae cells, however, reported the expression of $\mathrm{HN}$ protein as an insoluble inclusion body in E. coli. A secreted form of $\mathrm{HN}$ protein, which lacked the regions encoding the cytoplasmic tail and the transmembrane anchor sequences, has been expressed in P. pastoris and secreted into the culture supernatant (Peeters et al., 2001). This yeast culture supernatant has been characterized by $\mathrm{HN}$-specific monoclonal antibodies in capture ELISA using a limited number of serum samples with low titer, thereby demanding further optimization and validation of the test (Peeters et al., 2001). Hence, the expression profile, glycosylation pattern and antigenic nature of $\mathrm{HN}$ obtained from yeast expression system could not be determined.

Each expression host used in recombinant protein production has unique codon usage pattern that determines the level and quality of a heterologous gene expression. In this study, we report the in-silico analysis of codon usage preference for HN gene of NDV in S. cerevisiae and P. pastoris, the two routinely used yeast expression systems and subsequent expression and characterization of $\mathrm{HN}$ gene from the most suitable yeast expression host.

\section{Materials and Methods}

Selection of suitable yeast system by synonymous codon usage analysis. To select most suitable yeast expression system for $\mathrm{rHN}$ protein production, in-silico comparison was done for codon usage biasness among $S$. cerevisiae and $P$. pastoris. The relative synonymous codon usage value (RSCU) determines peculiarity of codon usage and was calculated with CUSP tool (create codon usage table program) of European Molecular Biology Open Software Suit (Emboss) (Table 1). The RSCU value $<1.0$ indicates negative codon bias, i.e less abundant codon, and $>1.0$ indicates positive codon bias,

Table 1. Synonymous codon usage of NDV HN gene analyzed with CUSP

\begin{tabular}{ccccccc}
\hline Sr. No. & Codon & Amino acid & ${ }^{a}$ Fraction & b Frequency & ${ }^{\text {c Number }}$ & dRSCU \\
\hline 1 & AAA & K & 0.5 & 19.031 & 11 & 1 \\
2 & AAC & N & 0.44 & 19.031 & 11 & 0.88 \\
3 & AAG & K & 0.5 & 19.031 & 11 & 1 \\
4 & AAT & N & 0.56 & 24.221 & 14 & 1.12 \\
5 & ACA & T & 0.538 & 48.443 & 28 & 2.15 \\
6 & ACC & T & 0.173 & 15.571 & 9 & 0.69 \\
7 & ACG & T & 0.019 & 1.73 & 1 & 0.08 \\
8 & ACT & T & 0.269 & 24.221 & 14 & 1.08 \\
9 & AGA & R & 0.235 & 13.841 & 8 & 1.41 \\
10 & AGC & S & 0.164 & 17.301 & 10 & 0.98 \\
11 & AGG & R & 0.206 & 12.111 & 7 & 1.24 \\
12 & AGT & S & 0.148 & 15.571 & 9 & 0.89 \\
13 & ATA & I & 0.342 & 22.491 & 13 & 1.03 \\
14 & ATC & I & 0.395 & 25.952 & 15 & 1.18 \\
15 & ATG & M & 1 & 17.301 & 10 & - \\
16 & ATT & I & 0.263 & 17.301 & 10 & 0.79 \\
17 & CAA & Q & 0.4 & 10.381 & 6 & 0.8 \\
18 & CAC & H & 0.333 & 6.92 & 4 & 0.67 \\
19 & CAG & Q & 0.6 & 15.571 & 9 & 1.2 \\
\hline
\end{tabular}


Table 1. (continued)

\begin{tabular}{|c|c|c|c|c|c|c|}
\hline Sr. No. & Codon & Amino acid & ${ }^{\mathrm{a}}$ Fraction & ${ }^{b}$ Frequency & ${ }^{c}$ Number & ${ }^{\mathrm{d}} \mathrm{RSCU}$ \\
\hline 20 & CAT & $\mathrm{H}$ & 0.667 & 13.841 & 8 & 1.33 \\
\hline 21 & CCA & $\mathrm{P}$ & 0.233 & 12.111 & 7 & 0.93 \\
\hline 22 & CCC & $\mathrm{P}$ & 0.333 & 17.301 & 10 & 1.33 \\
\hline 23 & CCG & $\mathrm{P}$ & 0.167 & 8.651 & 5 & 0.67 \\
\hline 24 & CCT & $\mathrm{P}$ & 0.267 & 13.841 & 8 & 1.07 \\
\hline 25 & CGA & $\mathrm{R}$ & 0.176 & 10.381 & 6 & 1.06 \\
\hline 26 & CGC & $\mathrm{R}$ & 0.176 & 10.381 & 6 & 1.06 \\
\hline 27 & CGG & $\mathrm{R}$ & 0.176 & 10.381 & 6 & 1.06 \\
\hline 28 & CGT & $\mathrm{R}$ & 0.029 & 1.73 & 1 & 0.18 \\
\hline 29 & CTA & $\mathrm{L}$ & 0.13 & 10.381 & 6 & 0.78 \\
\hline 30 & СТC & $\mathrm{L}$ & 0.174 & 13.841 & 8 & 1.04 \\
\hline 31 & CTG & $\mathrm{L}$ & 0.109 & 8.651 & 5 & 0.65 \\
\hline 32 & СТT & $\mathrm{L}$ & 0.174 & 13.841 & 8 & 1.04 \\
\hline 33 & GAA & E & 0.565 & 22.491 & 13 & 1.13 \\
\hline 34 & GAC & $\mathrm{D}$ & 0.414 & 20.761 & 12 & 0.83 \\
\hline 35 & GAG & E & 0.435 & 17.301 & 10 & 0.87 \\
\hline 36 & GAT & D & 0.586 & 29.412 & 17 & 1.17 \\
\hline 37 & GCA & A & 0.417 & 25.952 & 15 & 1.67 \\
\hline 38 & GCC & A & 0.222 & 13.841 & 8 & 0.89 \\
\hline 39 & GCG & A & 0.167 & 10.381 & 6 & 0.67 \\
\hline 40 & GCT & A & 0.194 & 12.111 & 7 & 0.78 \\
\hline 41 & GGA & G & 0.205 & 13.841 & 8 & 0.82 \\
\hline 42 & GGC & G & 0.128 & 8.651 & 5 & 0.51 \\
\hline 43 & GGG & G & 0.385 & 25.952 & 15 & 1.54 \\
\hline 44 & GGT & G & 0.282 & 19.031 & 11 & 1.13 \\
\hline 45 & GTA & V & 0.39 & 27.682 & 16 & 1.56 \\
\hline 46 & GTC & V & 0.195 & 13.841 & 8 & 0.78 \\
\hline 47 & GTG & $\mathrm{V}$ & 0.244 & 17.301 & 10 & 0.98 \\
\hline 48 & GTT & V & 0.171 & 12.111 & 7 & 0.68 \\
\hline 49 & TAC & Y & 0.385 & 17.301 & 10 & 0.77 \\
\hline 50 & TAT & $\mathrm{Y}$ & 0.615 & 27.682 & 16 & 1.23 \\
\hline 51 & TCA & S & 0.213 & 22.491 & 13 & 1.28 \\
\hline 52 & TCC & $S$ & 0.082 & 8.651 & 5 & 0.49 \\
\hline 53 & TCG & S & 0.066 & 6.92 & 4 & 0.39 \\
\hline 54 & TCT & $S$ & 0.328 & 34.602 & 20 & 1.97 \\
\hline 55 & TGC & $\mathrm{C}$ & 0.583 & 12.111 & 7 & 1.17 \\
\hline 56 & TGG & $\mathrm{W}$ & 1 & 6.92 & 4 & - \\
\hline 57 & TGT & $\mathrm{C}$ & 0.417 & 8.651 & 5 & 0.83 \\
\hline 58 & TTA & $\mathrm{L}$ & 0.283 & 22.491 & 13 & 1.7 \\
\hline 59 & TTC & $\mathrm{F}$ & 0.591 & 22.491 & 13 & 1.18 \\
\hline 60 & TTG & $\mathrm{L}$ & 0.13 & 10.381 & 6 & 0.78 \\
\hline 61 & TTT & $\mathrm{F}$ & 0.409 & 15.571 & 9 & 0.82 \\
\hline 62 & TAA & * & 0 & 0 & 0 & - \\
\hline 63 & TAG & * & 1 & 1.73 & 1 & - \\
\hline 64 & TGA & * & 0 & 0 & 0 & - \\
\hline
\end{tabular}

Footnote: ${ }^{a}$ Fraction column shows the proportion of each of the synonymous codons (encoding the same amino acid). ${ }^{b}$ Frequency/1000 value represents the number of codons percent per 1000 bases in the input sequence. ${ }^{c}$ Number represents the number of occurrences of each codon. ${ }^{\mathrm{d}} \mathrm{RSCU}$ value is used to determine the relative synonymous codon usage.

i.e abundant codons, whereas RSCU value $=1.0$ denotes random or equal usage of codon.

Codon preference analysis. Codon preferences of NDV HN gene were compared for ratio of codon usage frequency $(1 / 1000)$ for $S$. cerevisiae and P. pastoris (obtained from http://www.kazusa.or.jp/ codon/) to evaluate the suitable host for the optimal expression of HN protein in host (Fig. 1). The ratio of usage preference $>2.0$ and $<0.5$ shows distinct usage differences between NDV and any 
(a)

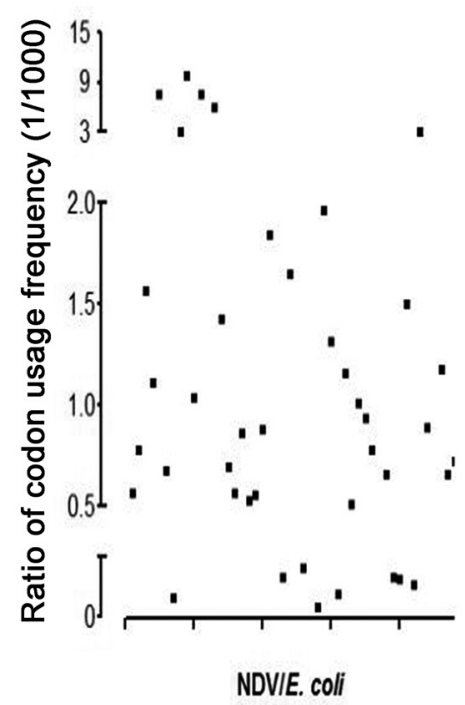

(b)

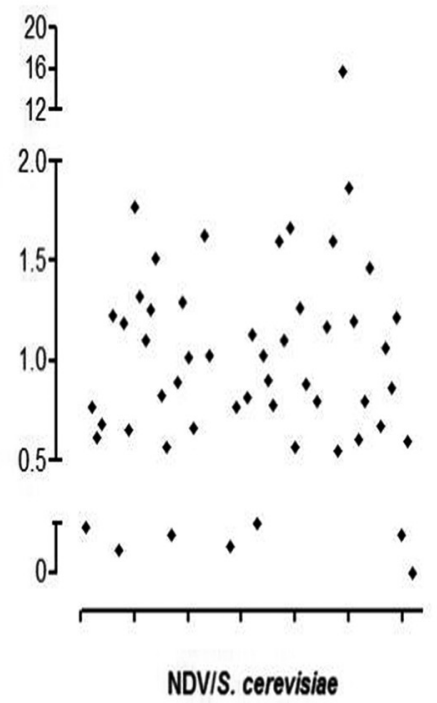

(c)

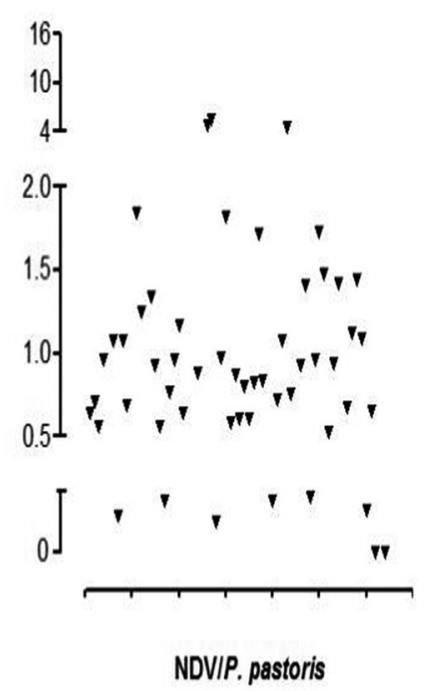

Fig. 1

Comparison of the ratio of codon usage frequency (1/1000) of NDV-HN gene to (a) E. coli (b) S. cerevisiae (c) P. pastoris Ratio higher than 0.5 and lower than 2 indicates similar codon usage preference.

heterologous expression system, whereas ratio between 0.5 and 2.0 denotes similar codon usage preference between the two systems.

Virus. The mesogenic NDV strain isolated from wild peacock characterized previously was used in this study (Khulape et al., 2014). The virus was maintained in the Recombinant DNA Laboratory, Indian Veterinary Research Institute. The virus was cultivated in the allantoic cavity of specific pathogen free 9-day-old embryonated chicken eggs and the infected allantoic fluid collected after $72 \mathrm{hr}$ of infection was used for RNA extraction.

Viral RNA extraction and RT-PCR. The RNA was extracted from allantoic fluid infected with NDV isolate using TRIZOL ${ }^{\oplus} \mathrm{LS}$ reagent as per manufacturer's instructions. The cDNA synthesis was performed using random hexamer primer with a SuperScript ${ }^{\circ}$ III first strand synthesis kit as per manufacturer's instructions (Invitrogen, USA).

Amplification and cloning of the HN gene. The complete coding sequence (CDS) of HN gene was amplified from cDNA by Taq DNA polymerase (Thermo Scientific, USA) using forward (HN-NotI5'-CCGCGGCCGCATGGACCGCGCAGTTAGC-3') and reverse (HN-BglII-5'-CCAGATCTCTAATGATGATGATGATGATGA CCAGACCTGGCTTCTCTAAC-3') primers with in-built restriction enzyme sites. The amplification was performed at an initial denaturation of $94^{\circ} \mathrm{C}$ for $5 \mathrm{~min}$, followed by 30 cycles of $94^{\circ} \mathrm{C}$ for $45 \mathrm{sec}, 55^{\circ} \mathrm{C}$ for $60 \mathrm{sec}, 72^{\circ} \mathrm{C}$ for $1 \mathrm{~min}$ and final extension of $72^{\circ} \mathrm{C}$ for $10 \mathrm{~min}$. The amplified product was cloned in $\mathrm{pTZ}$ 57R/T vector (Thermo Scietific, USA) following manufacturer's instructions. The $\mathrm{HN}$ cds was further subcloned into $\mathrm{pESC}$-URA expression vector (Stratagene, La Jolla, CA) downstream of the GAL10 promoter and named as pESC-URA-HN. The integrity of the plasmid at cloning and sub-cloning step was verified by restriction enzyme analysis and sequencing.

Expression and characterization of HNgene. The pESC-URA-HN plasmid was transformed into S. cerevisiae strain YH501 (Stratagene, La Jolla, CA) as described previously (Dey et al., 2009). The recombinant yeast clones were selected on auxotrophic SG-ura medium containing galactose, yeast extract without amino acids and amino acid drop out media (without uracil). The colonies were characterized for rHN protein expression by western blot assay. The blots were probed with in house chicken anti-NDV polyclonal antibody and detected with rabbit anti-chicken secondary antibody conjugated to HRP (Sigma, USA).

\section{Results}

\section{Selection of yeast expression host}

The RSCU analysis of HN gene (Table 1) of NDV showed that out of 61 codons, $29(47.5 \%)$ were used less abundantly, whereas $28(45.9 \%)$ codons were favored more frequently and only two codons were shown to be used randomly for expression of functional $\mathrm{HN}$ gene. Also, 45 and 42 number of codons with similar usage pattern were found when the expression of NDV HN protein was considered in S. cerevisiae and $P$. pastoris, respectively. This indicated that the codon usage of HN protein was more closely related to $S$. 


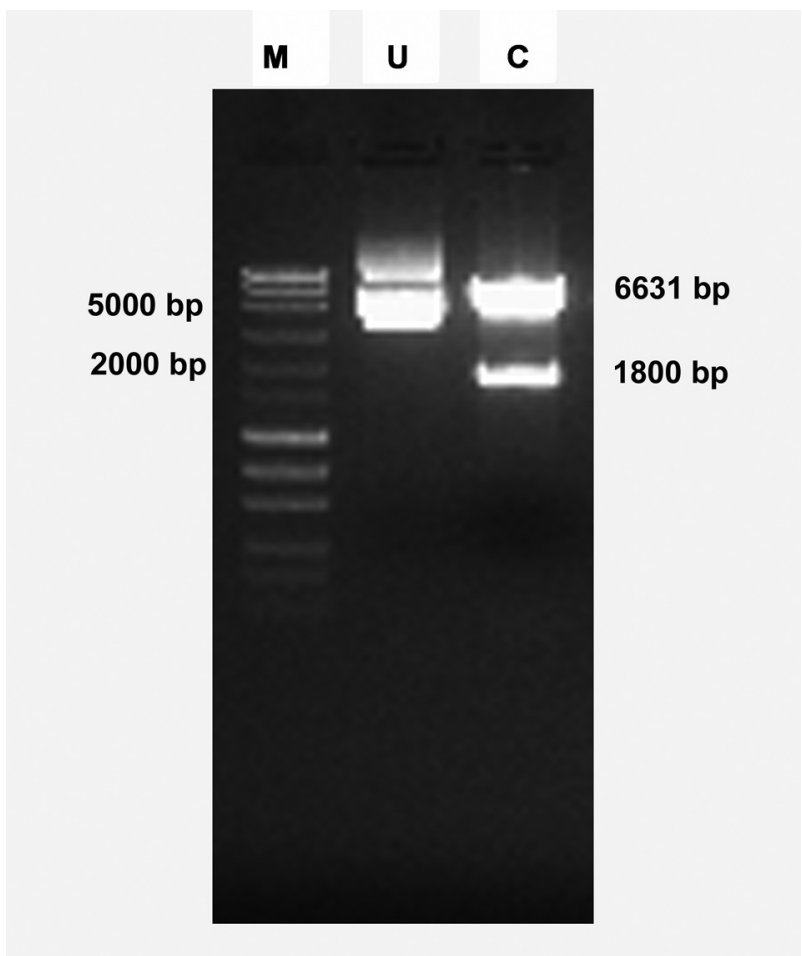

Fig. 2

Restriction enzyme screening of plasmid pESC-URA-HN Lane M: DNA molecular weight ladder; Lane U: Uncut pESC-URA-HN construct; Lane C: pESC-URA-HN construct following digestion with NotI and BglII released an insert of the size of HN gene ( 1800 bp) and pESC-URA vector (6631 bp).

cerevisiae than to $P$. pastoris. Further, it also revealed that $S$. cerevisiae can compensate for the codon usage pattern more effectively than $P$. pastoris.

\section{Amplification and cloning of HN gene}

To subclone the NDV HN gene, a specific amplicon of the size of approximately $1800 \mathrm{bp}$ was obtained by PCR, as expected. The amplified product was cloned in $\mathrm{pTZ} 57 \mathrm{R} / \mathrm{T}$ vector and subcloned into the pESC-URA vector. The restriction enzyme analysis of pESC-URA-HN using NotI and BglII showed specific release of $\mathrm{HN}$ cds (Fig. 2).

\section{Expression of HN protein in S. cerevisiae}

Western blot analysis of yeast cell lysate showed that $\mathrm{rHN}$ protein reacted specifically as a double band pattern with the molecular weight between $50 \mathrm{kDa}$ and $80 \mathrm{kDa}$ when probed with polyclonal sera against NDV (Fig. 3). The banding pattern obtained for $\mathrm{rHN}$ protein corresponds to differential glycosylation extent in the yeast cell.

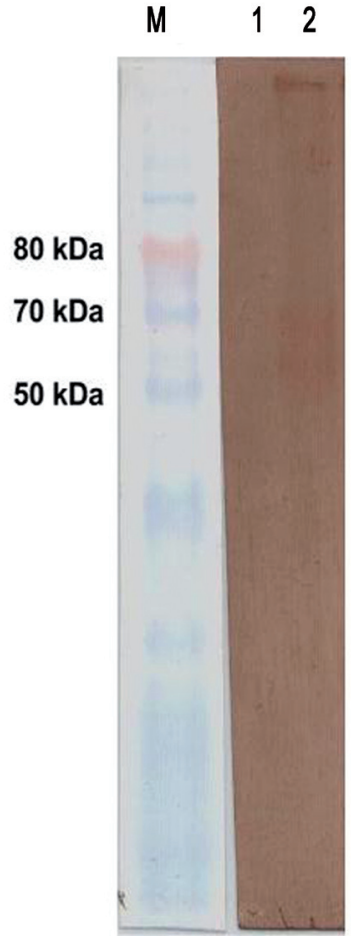

Fig. 3

Recombinant HN protein detected by Western blot assay Lane M: Prestained marker; Lane 1: Empty pESC-URA vector transformed in yeast cells; Lane 2: Yeast cell lysate transformed with pESC-URA-HN plasmid.

\section{Discussion}

Recombinant antigens derived from various expression systems have become integral part for development of immunoassays and vaccines, overcoming the shortfalls of traditional antigen preparation protocols with respect to quality, convenience and time. We report the successful expression of complete HN gene of NDV in S. cerevisiae, a yeast expression system. As an outer membrane glycoprotein, NDV HN plays a pivotal role in infection and immunity of the host. Sialic acid receptors on host cells are recognized by $\mathrm{HN}$ protein that leads to the virus attachment (Scheid and Choppin, 1973). Additional neuraminidase activity of $\mathrm{HN}$ protein helps in hydrolysis of progeny's sialic acid to prevent selfagglutination. HN protein is necessary for penetration of the virus into the cell and determines the tropism and virulence of the virus (Huang et al., 2004). Thus, HN protein has been targeted for the development of recombinant-antigen based diagnostics and subunit vaccines.

The HN protein of NDV has been previously expressed in a common prokaryotic expression system E. coli (Mo- 
han et al., 2006). The recombinant protein obtained from prokaryotic host was compromised for glycosylation, activity and yield, thus has an undesirable property towards production of a subunit vaccine. A well-qualified baculovirus-based eukaryotic system has been also explored for production of $\mathrm{rHN}$ protein but the utility was hindered due to the failure to achieve high cell densities, limiting the potential productive capacity of the host (Radford et al., 1997).

The yeast expression of complete $\mathrm{HN}$ gene has been attempted earlier but the expression profile, glycosylation pattern and antigenic nature of rHN protein could not be determined (King, 2004). The study was carried out to express the complete HN gene in a yeast. $S$. cerevisiae and $P$. pastoris, the two commonly used yeast hosts were compared in-silico to select the best suitable system for expression of HN gene based on synonymous codon usage analysis. This codon usage preference varies with the species and determines the degree of heterologous gene expression in the host (Wang et al., 2011). Additionally, this specific inclination for particular codon usage is essential in understanding the evolution of pathogen and subsequently for the expression of immunogenic proteins in the most desirable expression system. Both mutational bias and natural selection determine the codon usage pattern of a particular gene and in case of NDV, the mutational pressure is considered as the main factor (Wang et al., 2011).

The codon usage of HN protein was found to be more closely related to that of $S$. cerevisiae than to that of $P$. pastoris. Hence, we speculated that $S$. cerevisiae could be a better expression system than $P$. pastoris with wide range of strains available, together with eliminating the problem of methanol toxicity as observed during induction of $P$. pastoris. The antigenic analysis based on Western blot of yeast lysate showed specific reactivity of $\mathrm{rHN}$ protein. The banding pattern obtained for $\mathrm{rHN}$ protein corresponds to differential glycosylation extent in yeast cell. The glycosylation heterogeneity for $\mathrm{rHN}$ protein has previously been reported following expression in an insect cell line using baculovirus vector system (Zoth et al., 2011).

To the best of our knowledge, this is the first report wherein the complete cds of HN gene was expressed in the yeast $S$. cerevisiae. The yeast cells were able to generate glycosylated HN protein with proper folding and antigenicity. Since the HN expressed in this study was also tagged with $6 \times$ histidine, Ni-NTA column was used for affinity purification of the protein. This allowed the protein to be obtained in a pure form, which can be further employed for use as subunit vaccine or as an antigen-based diagnostic test. The present study validates yet another system for efficient expression of $\mathrm{HN}$ that could also be explored for expression of other outer membrane glycoprotein of NDV.

\section{References}

Alexander DJ, Senne DA (2008): Newcastle disease, other avian paramyxoviruses, and pneumovirus infections. In Saif YM, Fadly AM, Glisson JR, Mc-Dougald LR, Nolan LK, Swayne DE (Eds): Diseases of Poultry. Iowa State University Press, Ames, pp. 75-116.

Cosset FL, Bouquet JF, Drynda A, Chebloune Y, Rey-Senelonge A, Kohen G, Nigon VM, Desmettre P, Verdier G (1991): Newcastle disease virus (NDV) vaccine based on immunization with avian cells expressing the NDV hemagglutinin-neuraminidase glycoprotein. Virology 185, 862-866. http://dx.doi.org/10.1016/0042-6822(91)90560-X

Dey S, Upadhyay C, Madhan Mohan C, Kataria JM, Vakharia VN (2009): Formation of subviral particles of the capsid protein VP2 of infectious bursal disease virus and its application in serological diagnosis. J. Virol. Methods 157, 84-89. http://dx.doi.org/10.1016/j.jviromet.2008.11.020

Dey S, Chellappa MM, Gaikwad S, Kataria JM, Vakharia VN (2014): Genotype characterization of commonly used Newcastle disease virus vaccine strains of India. PLoS ONE 9, e98869. http://dx.doi.org/10.1371/journal.pone.0098869

Gribskov M, Devereux J, Burgess R (1984): The codon preference plot: graphic analysis of protein coding sequences and prediction of gene expression. Nucleic Acids Res. 12, 539-549. http://dx.doi.org/10.1093/nar/12.1Part2.539

Huang Z, Panda A, Elankumaran S, Govindarajan D, Rockemann DD, Samal SK (2004): The hemagglutinin-neuraminidase protein of Newcastle disease virus determines tropism and virulence. J. Virol. 78, 4176-4184. http://dx.doi. org/10.1128/JVI.78.8.4176-4184.2004

Khulape SA, Gaikwad SS, Chellappa MM, Mishra BP, Dey S (2014): Complete genome sequence of a newcastle disease virus isolated from wild peacock (Pavo cristatus) in India. Genome Announc. 2, e00495-14. http://dx.doi.org/10.1128/ genomea.00495-14

King WS (2005): Ph.D. Thesis entitled "Production of recombinant envelope proteins of Newcastle disease virus in Escherichia coli and analysis of their immunological properties", submitted to University Putra Malaysia.

Krishnamurthy S, Samal SK (1998): Nucleotide sequences of the trailer, nucleocapsid protein gene and intergenic regions of Newcastle disease virus strain Beaudette $\mathrm{C}$ and completion of the entire genome sequence. J. Gen. Virol. 79, 2419-2424. http://dx.doi.org/10.1099/0022-1317-79-10-2419

Lee Y, Sung H, Choi J, Lee E, Yoon H, Kim J, Song C (2008): Protection of chickens from Newcastle disease with a recombinant baculovirus subunit vaccine expressing the fusion and haemagglutinin-neuraminidase proteins. J. Vet. Sci. 9, 301-308. http://dx.doi.org/10.4142/jvs.2008.9.3.301

Long L, Portetelle D, Ghysdael J, Gonze M., Burny A., Meulemans G (1986): Monoclonal antibodies to hemagglutininneuraminidase and fusion glycoproteins of Newcastle disease virus: relationship between glycosylation and reactivity. J. Virol. 57, 1198-1202.

Mattanovich D, Branduardi P, Dato L, Gasser B, Sauer M, Porro D (2012): Recombinant protein production in 
yeasts.Methods Mol. Biol. 824, 329-358. http://dx.doi. org/10.1007/978-1-61779-433-9 17

Mayo MA (2002): A summary of taxonomic changes recently approved by ICTV. Arch. Virol. 147, 1655-1656. http:// dx.doi.org/10.1007/s007050200039

Mohan CM, Dey S, Rai A, Kataria JM (2006): Recombinant haemagglutinin neuraminidase antigen-based single serum dilution ELISA for rapid serological profiling of Newcastle disease virus. J. Virol. Methods 138, 117-122. http:// dx.doi.org/10.1016/j.jviromet.2006.08.002

Nagy E, Krell PJ, Dulac GC, Derbyshire, JB (1991): Vaccination against Newcastle disease with a recombinant baculovirus hemagglutinin-neuraminidase subunit vaccine. Avian Dis. 35, 585-590. http://dx.doi.org/10.2307/1591224

Niikura M, Matsuura Y, Hattori M, Onuma M, Mikami T (1991): Characterization of haemagglutinin-neuraminidase glycoprotein of Newcastle disease virus expressed by a recombinant baculovirus. Virus Res. 20, 31-43. http:// dx.doi.org/10.1016/0168-1702(91)90059-5

Ong HKA, Ali AM, Omar AR, Tan WS, Yusoff K (1999): N-linked glycosylated $\mathrm{HN}$ protein of NDV strain AF2240 expressed in Baculovirus-infected Sf 9 cells. J. Biochem. Mol. Biol. Biophys. 3, 147-151.

Peeters B, Leeu WO, Vertegen I, Koch G, Gielkens A (2001): Generation of a recombinant chimeric Newcastle disease virus vaccine that allows serological differentiation between vaccinated and infected animals. Vaccine 19, 1616-1627. http://dx.doi.org/10.1016/S0264-410X(00)00419-9

Radford KM, Reid S, Greenfield PF (1997): Substrate limitation in the baculovirus expression vector system. Biotechnol.
Bioeng. 56, 32-44. http://dx.doi.org/10.1002/(SICI)10970290(19971005)56:1<32::AID-BIT4>3.0.CO;2-W

Sawant PM, Verma PC, Subudhi PK, Chaturvedi U, Singh M, Kumar R, Tiwari A (2010): Immunomodulation of bivalent Newcastle disease DNA vaccine induced immune response by co-delivery of chicken IFN- $\gamma$ and IL- 4 genes. Vet. Immunol. Immunopathol. 144, 36-44. http://dx.doi. org/10.1016/j.vetimm.2011.07.006

Schaper UM, Fuller FJ, Ward MDW, Mehrotra Y, Stone HO, Stripp BR, Debuyssche EV, 1988. Nucleotide sequence of the envelope protein genes of highly virulent, neurotropic strain of Newcastle disease virus. Virology 165, 291-295. http://dx.doi.org/10.1016/0042-6822(88)90686-1

Scheid A, Choppin PW (1973): Isolation and purification of envelope protein of NDV. J. Virol. 11, 263-271.

Wang KY, Kathleen MH, Karl A, Richard C, Wafaa M, Manon MJC (2006): Expression and purification of influenza hemagglutinin-One step closer to a recombinant proteinbased influenza vaccine. Vaccine 24, 2176-2185. http:// dx.doi.org/10.1016/j.vaccine.2005.11.005

Wang M, Liu YS, Zhou JH, Chen HT, Ma LN, Ding YZ, Liu WQ, Gu YX, Zhang J (2011): Analysis of codon usage in Newcastle disease virus. Virus Genes 42, 245-253. http://dx.doi. org/10.1007/s11262-011-0574-Z

Zoth SC, Gómez E, Carballeda JM, Carrillo E, Berinstein A (2011): Expression of a secreted version of the hemagglutinin-neuraminidase glycoprotein of Newcastle disease virus: its evaluation as a diagnostic reagent. J. Vet. Diagn. Invest. 23, 519-523. http://dx.doi. org/10.1177/1040638711404153 